\title{
Microstructural Modeling of Glass Cullet Reaction in
}

\section{Cementitious Systems}

\author{
Mohammadreza Mirzahosseini ${ }^{1}$
}

\begin{abstract}
Finely ground glass has the potential for pozzolanic reactivity and can serve as a supplementary cementitious material (SCM). Glass reaction kinetics depends on both temperature and glass composition. Microstructural modeling is a helpful approach to get better understanding of cement hydration and microstructure development. Mechanical and performance properties of concrete are directly related to the development of concrete microstructure, which is the consequence of progress in cement hydration. This study initially provides a comprehensive background about cement hydration process and microstructural modeling of the hydration. It then utilizes results of experimental studies, i.e. isothermal calorimetry and thermogravimetric analysis, to find kinetics equation parameters called "Avrami Constants". For the first time, these constants were found for three main components of cement, i.e. $\mathrm{C}_{3} \mathrm{~S}, \mathrm{C}_{2} \mathrm{~S}$, and $\mathrm{C}_{3} \mathrm{~A}$, and also for glass particles smaller than $25 \mu \mathrm{m}$. Although modeling of cement hydration and cementitious systems containing single glass particles showed promising results, simulations of combined glass types and sizes showed that more work on microstructural models is needed to properly model the reactivity of mixed glass particle systems.
\end{abstract}

Keywords: Microstructural modeling, cement hydration, Avrami constants, hydration kinetics, glass cullet, supplementary cementitious material (SCM)

\footnotetext{
${ }^{1}$ Post-Doctoral Researcher at Purdue University, West Lafayette, IN
} 


\section{Introduction}

\section{Cement Hydration}

Concrete is the second most commonly used industrial material in the world after water [1]. Concrete typically contains water, cement, coarse aggregates, and fine aggregates. Portland cement is the world's most commonly used cement in concrete. Global production and consumption of portland cement have been increased within past years [2]. In 2012, cement consumption throughout the world were 3736 million tons [1]. Cement hydration is the fundamental process which is responsible for heat release, strength gain, and microstructural development of concrete [3]. Clinker contains four main compounds (Table 1) whose proportions depend on the raw materials proportion and the temperature in the kiln.

Table 1. Four main compounds of portland cement

\begin{tabular}{lll}
\hline Compound & Notation $^{\mathbf{1}}$ & Phase Name \\
\hline Tricalcium Silicate & $\mathrm{C}_{3} \mathrm{~S}$ & Alite (impure version of $\mathrm{C}_{3} \mathrm{~S}$ ) \\
Dicalcium Silicate & $\mathrm{C}_{2} \mathrm{~S}$ & Belite (impure version of $\mathrm{C}_{2} \mathrm{~S}$ ) \\
Tricalcium Aluminate & $\mathrm{C}_{3} \mathrm{~A}$ & Aluminate \\
Tetracalcium Aluminoferrite & $\mathrm{C}_{4} \mathrm{AF}$ & Ferrite \\
1. $\mathrm{C}: \mathrm{CaO}, \mathrm{S}: \mathrm{SiO}_{2}, \mathrm{~A}: \mathrm{Al}_{2} \mathrm{O}_{3}$, and $\mathrm{F}: \mathrm{Fe}_{2} \mathrm{O}_{3}$ &
\end{tabular}

The principle hydration reactions of the main compounds of clinker are shown in Eq. (1) through Eq. (4).

$$
\begin{array}{lc}
\mathrm{C}_{3} \mathrm{~S}+5.3 \mathrm{H} \rightarrow \mathrm{C}-\mathrm{S}-\mathrm{H}+1.3 \mathrm{CH} & \text { Eq. (1) } \\
\mathrm{C}_{2} \mathrm{~S}+4.3 \mathrm{H} \rightarrow \mathrm{C}-\mathrm{S}-\mathrm{H}+0.3 \mathrm{CH} & \text { Eq. (2) } \\
\mathrm{C}_{3} \mathrm{~A}+3 \mathrm{C} \$ \mathrm{H}_{2}+26 \mathrm{H} \rightarrow \mathrm{C}_{6} \mathrm{~A}_{3} \mathrm{H}_{32} & \text { Eq. (3) } \\
\mathrm{C}_{4} \mathrm{AF}+3 \mathrm{C} \$ \mathrm{H}_{2}+21 \mathrm{H} \rightarrow \mathrm{C} 6(\mathrm{~A}, \mathrm{~F}) \$_{3} \mathrm{H}_{32}+(\mathrm{F}, \mathrm{A}) \mathrm{H}_{3} & \text { Eq. (4) } \\
\text { The } \$ \text { is used in cement chemist notation to denote sulfate. The hydration of } \mathrm{C}_{3} \mathrm{~S}_{3} \text { and } \mathrm{C}_{2} \mathrm{~S}
\end{array}
$$




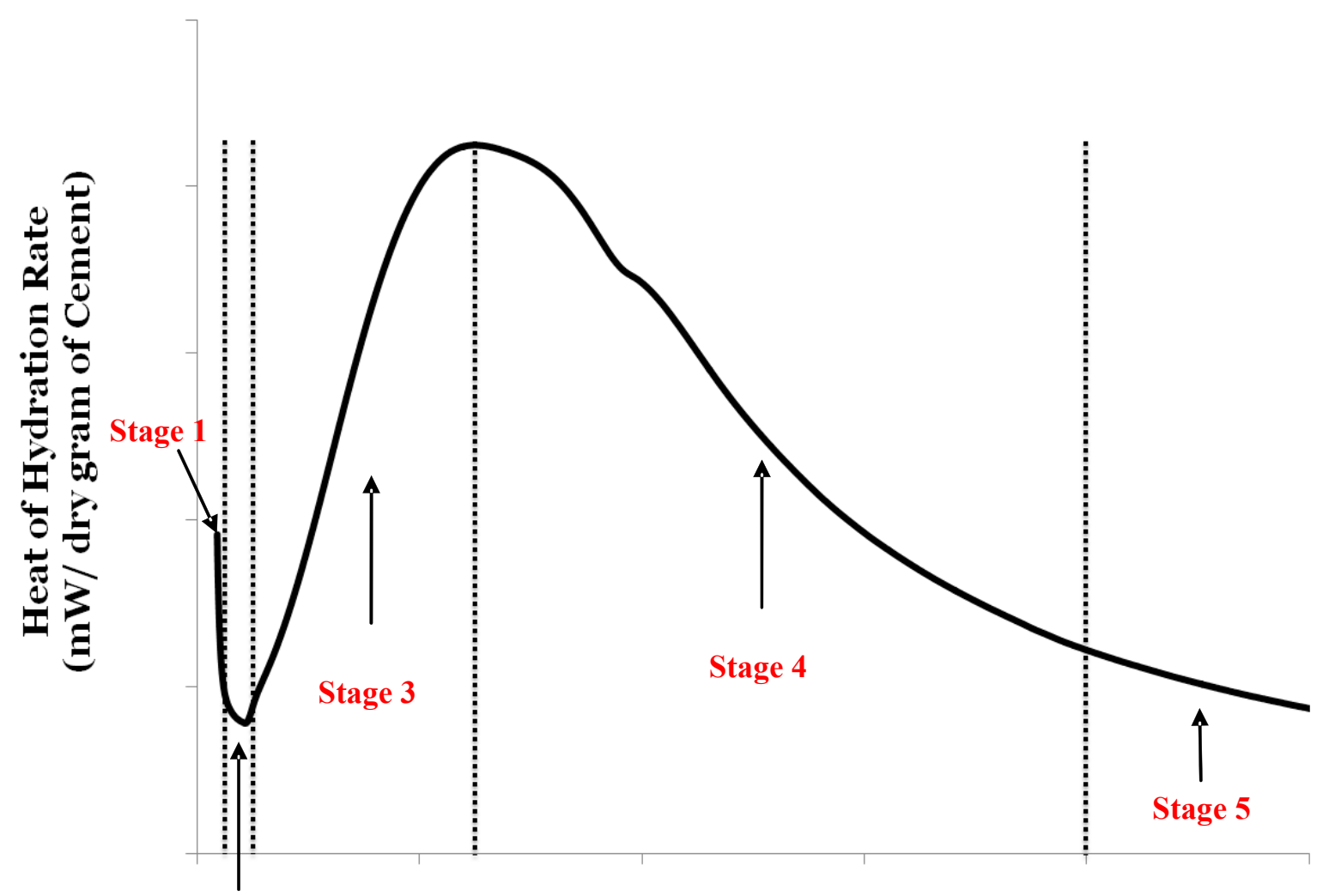
Figure 1. Hydration heat curve of portland cement paste

During these reactions, each of these four phases releases some heat, making hydration an exothermal chemical reaction [4]. Monitoring and measuring the amount of heat evolved during cement hydration can provide valuable information to investigate mechanical and performance properties of concrete. Figure 1 shows the isothermal heat of hydration $(\mathrm{HOH})$ of a portland cement. There are five distinct reaction stages shown in Figure 1: dissolution, induction, acceleration, deceleration, and the transition/diffusion-controlled stage [4]. Comprehensive explanations of these stages are available in the literatures [4,5,6-28].

Stage 2

\section{Time from Mixing (Hr)}

\section{Factors Affecting Hydration Rate}

Hydration rate varies for different cementitious materials, mixture properties, and conditions. Chemical compositions of cementitious materials, w/cm, applied pressure, particle 
sizes of cementitious materials, and curing temperature can all affect the rate of hydration of cementitious materials [3]. In the case of portland cement, different amounts of $\mathrm{C}_{3} \mathrm{~S}, \mathrm{C}_{2} \mathrm{~S}, \mathrm{C}_{3} \mathrm{~A}$, and $\mathrm{C}_{4} \mathrm{AF}$ result in different hydration heat (Table 2). $\mathrm{C}_{3} \mathrm{~S}$ and $\mathrm{C}_{3} \mathrm{~A}$ have the highest rate of reaction and produce the greatest amount of heat per unit quantity in the cement [29].

\section{Table 2. Amount of heat produced per gram of each phase}

\begin{tabular}{ll}
\hline Phases & Hydration heat $(\mathbf{J} / \mathbf{g})$ \\
\hline $\mathrm{C}_{3} \mathrm{~S}$ & 500 \\
$\mathrm{C}_{2} \mathrm{~S}$ & 260 \\
$\mathrm{C}_{3} \mathrm{~A}$ & 866 \\
$\mathrm{C}_{4} \mathrm{AF}$ & 420 \\
\hline
\end{tabular}

Another important factor is $\mathrm{w} / \mathrm{cm}$ ratio which not only affects the hydration rate, but also influences the degree of hydration $(\mathrm{DOH})$ and strength gain of concrete. Higher w/cm ratios enhance the cement rate of hydration during the acceleration period [30,31]. Particle size plays an important role in hydration rate. As general rule, smaller particle sizes of cementitious systems and finer cement can increase the rate of hydration [29,32-34]. Finer cementitious materials have higher specific surface providing more available area to water and causing higher hydration rate. Higher surface area of cementitious system has been found to produce thinner hydration product resulting in higher final degree of hydration [3]. Influence of curing temperatures of the reaction rate of cementitious materials can be surveyed from two aspects. First of all, elevated curing temperatures can enhance the rate of hydration $[35,36]$. However, higher curing temperatures can cause rapid formation of hydration products which means that the hydration gradually shifts to a diffusion-controlled mechanism. This phenomenon makes it hard for water to access unreacted cementitious materials and results in a lower rate of reaction at later ages and lower ultimate hydration degree [3,37]. 


\section{Supplementary cementitious Materials (SCM)}

Cement production is an energy-intensive process and responsible for 5-8\% of global manmade $\mathrm{CO}_{2}$ emissions [38]. One of the most effective ways to reduce greenhouse gas emission and consumed energy from the cement industry is to partially substitute cement by other siliceous and aluminosiliceous material, known as Supplementary Cementitious Materials (SCM) [5,38]. SCMs can improve the properties of hardened concrete containing SCMs through the pozzolanic reaction. The pozzolanic reaction occurs when the $\mathrm{CH}$ reacts with amorphous silica of SCMs and water to create more C-S-H gel. A typical form of the pozzolanic reaction can be expressed as Eq. (5):

$\mathrm{Ca}(\mathrm{OH})_{2}+\mathrm{SiO}_{2}+\mathrm{H}_{2} \mathrm{O} \rightarrow(\mathrm{CaO})\left(\mathrm{SiO}_{2}\right)\left(\mathrm{H}_{2} \mathrm{O}\right)$

From a mechanical point of view, SCMs can increase the concrete ultimate compressive strength. Lothenbach et al. [39] have shown that SCMs can improve concrete microstructure through changes in C-S-H composition and changes in the porosity. The changes in the C-S-H composition however depend on the SCM composition. One material which has been studied for potential use as an SCM in concrete is waste glass cullet.

\section{Glass Cullet in Concrete}

Millions of tons of glass cullet are either landfilled or recycled throughout the world every year [40]. However, landfilling has economic and environmental issues such as limited capacity [41]. Additionally, recycling has also drawbacks such as not being able to recycle mixed color glass [42]. As the economic and environmental consequences of landfilling and recycling rise, the incentive to reuse glass cullet has grown. The concrete industry is one of the potential ways of reusing millions of tons of glass cullet per year either as aggregate or SCM [43]. Several studies have shown that glass behaves pozzolanically if ground finely enough, with a surface area of more than $300 \mathrm{~m}^{2} / \mathrm{kg}$ [44-50]. Most studies on the effect of glass cullet on cementitious mixtures as an 
SCM focused on mechanical and durability properties [51-54]. There are few studies which have aimed to connect the microstructural properties of cementitious mixture containing glass powder to performance characteristics of the glass mixtures. Federico [55] performed an extensive study on the influence of glass powder on reaction kinetics and performance properties of cementitious mixtures.

\section{Introduction to Microstructural Modeling of Hydration Process}

Microstructural modeling is a helpful tool to obtain better understanding of cement hydration and microstructure development [6]. Mechanical and performance properties of concrete are directly related to the development of concrete microstructure, which is the consequence of progress in cement hydration $[6,56]$. Cement hydration is a complicated system making hydration difficult to model [57]. This complexity is the main reason for which there has not been developed a complete theory explaining cement hydration and chemical reaction, despite almost 200 years having passed from invention of cement [58]. Nevertheless, many efforts have been made during the past 40 years to microstructurally model hydration of cement and various cementitious materials such as fly ash, slag, and SF [57-63]. For the first time, this study has used a recentlydeveloped modeling platform called " $\mu$ ic the model" to model kinetics reactions of three main phases of cement, i.e. $\mathrm{C}_{3} \mathrm{~S}, \mathrm{C}_{2} \mathrm{~S}$, and $\mathrm{C}_{3} \mathrm{~A}$, and to simulated pozzolanic reactivity of single type and fraction size and combined types and particle sizes of finely ground glass cullet.

\section{Background of Microstructural Modeling}

\section{Single Particle Model}

The Single Particle Model was developed based on growing hydration products in layers on single spherical particles by Kondo and Kodama in 1967 [64]. This model suggested that the 
first layer of hydration products creates a protective layer, making dissolution harder and ending the induction period. This layer is then consumed and acceleration period begins. Clifton et al. [65] proposed a diffusion-based single particle model for $\mathrm{C}_{3} \mathrm{~S}$ which has similar fundamentals to the Kondo and Kodama's model [64]; but has stronger mathematical bases. The strong point of this model is its ability to account for the continuous integrity of products layers through the boundaries. In addition to the mathematical models, some single-particle-based empirical models have been developed. Parrot and Killoh [66] performed an X-ray diffraction (XRD) analysis to extract a dissolution model considering cement types and sizes, w/cm, and relative humidity (RH). Tomosawa [67] proposed an empirical model which is similar to Parro and Killoh's [66], and takes into account the effect of fineness of cement particles and w/cm on cement reaction kinetics. Both of these empirical models are effective with spherical shapes and easy to be executed. However, these empirical models are just valid for the property ranges used to develop the models and need to be calibrated for other materials properties. The major drawbacks of the single particle model are that the models are not able to consider interaction between particles and cannot evaluate total cement reaction kinetic for different size ranges.

\section{Nucleation and Growth Models}

C-S-H nucleation and growth are consider and modeled as one process using Nucleation and Growth models, despite they are two different mechanisms. The first type of Nucleation and Growth model is Early Nucleation and Growth considering two main cases: site saturation and continuous nucleation [64]. Site saturation happens when nucleation is very quick at the beginning of hydration but suddenly stops. Continuous nucleation occurs when nucleation sites are not fully consumed. The simplest and the most widely used nucleation and growth model is Johnson and Mehl, Avrami, and Kolmogorov (JMAK) model typically used for $\mathrm{C}_{3} \mathrm{~S}$ modeling. This model utilizes mathematical rules to explain hydration products overlapping. The JMAK model however, 
is not capable of providing physically meaningful parameters, is just valid in isothermal conditions, and is not able to take into account the impact of cement surface area as an important criterion of particle sizes on reaction rate. Regardless of these limitations, many researchers have implemented the JMAK model to study different aspects of cement hydration. The first application of the JMAK model is dated back to 40 years ago when Tenatousse and de Donder [68] used the model to find out that the nucleation and growth process is not limited to the acceleration period and can be considered as a contributing process during the deceleration period. Models proposed by Brown et al. [69] and Gartner and Gaidis [70] are the other examples of using JMAK model. The model by Brown et al.did not show conclusive results. The model by Gartner and Gaidistried to cast doubt on spatial nucleation hypothesis in the JMAK model but it was not accepted. One of the other approaches in nucleation and growth modeling is the Mathematical Boundary Nucleation and Growth (BNG) model originally developed by Chan in 1956 [71]. This model assumes that C-S$\mathrm{H}$ nucleation occurs merely on arbitrarily oriented and dispersed planar borders. A recent study [72] showed that BNG models can deliver more significant and realistic results compared to the JMAK models. On the other hand, the BNG model is just an estimation which means that the exact boundary condition would not be evaluated and hydration of $\mathrm{C}_{3} \mathrm{~S}$ is only accounted for. Additionally, the BNG model is developed for a fixed surface area which is not true in real world.

\section{Hydration Simulation Model}

It should be noted that this type of models has a significant difference with those mentioned above. The single particle and nucleation and growth models are mathematical models based on scientific theory, whereas simulation models are the visualized applications of those principals. Currently, advances in computer technologies have paved the way for researchers to study complicated hydration of cementitious materials accurately and in more details [64]. The first simulation model was developed by Frohnsdorff et al. [73]. Although this model did not broad 
169

application until next 20 years, it could be fairly successful in simulating hydration kinetics and formation of microstructure. The first published simulation model was in 1986 called the Jennings and Johnson Microstructure Simulation model. They developed a 3D platform which utilized an off-Lattice (Vector) approach to simulated cement hydration. Off-Lattice is a method of presenting different shapes using their properties. Cement particles were simulated by spherical particles randomly distributed in the paste cube. Hydration was also simulated through the decrease in radius of reactant particles as hydration progresses, and an increase in thickness of hydration products on the reactants' surface. This proposed simulation model was capable of taking into account many complicated mechanisms such as different particle sizes, overlapping phenomenon, and position and quantity of $\mathrm{CH}$ crystals. However, the model had restricted computational abilities making it not broadly advanced and implemented. Another simulation model developed is the HymoStruc (HYdration, Morphology, and STRUCtural development) model developed by Van Breugel [74]. This model utilizes a 3D platform for modeling, is traceable from computational point of view, and uses the same principal as Jennings and Johnson's for cement hydration. Though the model had many shortcomings such as the model was able to simulated just one product, did not explain the influence of pore solution, did not calculate overlapping phenomenon, and the reaction rate was a function of particle size only. One of the fairly successful simulation models was CEMHYD3D Digital Hydration model developed by Bentz and Garboczi [75]. This model uses a 3D lattice-based platform on digital images. The discrete element approach was implemented in this model. The model operates quickly, and is able to simulate non-spherical cement particles. Additionally, the simulation model incorporates a broad range of phenomena such as hydration heat, porosity, chemical shrinkage, setting time, and the effect of environmental conditions on microstructural development. Not having a physical time scale and thermodynamic information, as well as necessity of calibration of time scale and not being numerically convergent are of the foremost drawbacks of the CEMHYD3D model. In order to solve some of drawbacks of 
194

previous simulation models like restrictions of kinetics, limited implementation of different materials, and deficiency of CEMHYD3D regarding convergence a series of probabilistic rules were used by Bullard [76] to develop a stochastic simulation model known as HydratiCA Simulation model. This model is capable of simulating dissolution, nucleation, growth, and diffusion processes, as well as complicated reactions that happen in pore solutions. The two biggest advantages of this model are: the ability of the model to deliver an accurate prediction of hydration kinetics based on chemistry of solutions and temperatures, and user does not need to make any modifications in parameters during simulation. The main drawback of this model is that the model is cumbersome and computationally expensive, as several required inputs are needed to be specified at the beginning of simulation. The last simulation model discussed in this study is the multi-scale finite element-based model, called DuCom Hydration model which was developed by University of Tokyo. This semi-empirical model was used to predict structures' durability. This model was a constructional model rather than a microstructural one. The main disadvantages of this model were its dependency on merely empirical relations and using single particle approach to simulate hydration [6]. Although many researches have carried out on microstructural modeling of cement hydration, more work is still needed to obtain an accurate and comprehensive model which is able to evaluate field performance of concrete, address material-related problems, and simulate new cementitious materials.

\section{$\mu$ ic the Model}

The principles of the $\mu$ ic (reads mike) were obtained from the approach outlined by Navi and Pignat [77]. $\mu$ ic has been designed in a way that it can be improved as our knowledge of cement progresses. $\mu$ ic is a customizable modeling platform that enables users to model new cementitious materials and reaction algorithm, to extensively develop in the future, to easily interact with a friendly environment, to simulate a wide range of particles sizes as an influential 
factor in cement hydration, and to use the model in regular computers. $\mu$ ic utilizes a fast and resolution-free approach called "Vector Approach". Vector approach, versus discrete approach, is a widely accepted method using locations and sizes of objects to define objects' geometry and to simulate multi-scale materials like cement. However, since vector approach is expensive from computational aspect some simplifying suppositions have been taken into account like spherical approximation, statistical homogeneity, and reduced particle size distribution. Among these three suppositions, spherical approximation has been executed for $\mu$ ic to make the model faster, as the sphere is the most regular shape and has fastest computation time. Object-oriented programming in Java also has been utilized in $\mu$ ic, as the most effective method for cement hydration to make $\mu$ ic operate faster. This is achieved by storing information in diverse assemblies without noticeable increases in required memory. $\mu$ ic simulates cement grains as spherical particles with determined radius and initial coordination in a virtual computational cube. Cement hydration is then simulated through decrease in radius of reacting particles, and simultaneous formation of hydration products in different layers on available surface of unreacted phases or in porosities. In addition to nucleation and growth of hydration products and by-products, overlapping of hydration products is also included.

\section{Experimental Program}

\section{Materials}

\section{Cement and Water}

An ASTM C150 [78] Type I/II ordinary portland cement (OPC) was used in this study. Table 3 shows the cement chemical composition as determined by X-ray fluorescence (XRF) analysis. Potential primary cement components used in this study, calculated by Bogue equations 
[78] and Rietveld analysis of XRD are summarized in Table 4. Distilled water was also used as

241 mixing water for this study.

Table 03. Chemical components of cementitious materials

\begin{tabular}{lcccccccc}
\hline $\begin{array}{l}\text { Cementitious } \\
\text { Materials }\end{array}$ & \multicolumn{7}{c}{ Chemical Components } \\
\cline { 2 - 8 } & $\mathrm{SiO}_{2}(\%)$ & $\mathrm{Al}_{2} \mathrm{O}_{3}(\%)$ & $\mathrm{CaO}(\%)$ & $\mathrm{Na}_{2} \mathrm{O}(\%)$ & $\mathrm{K}_{2} \mathrm{O}(\%)$ & $\mathrm{Cr}_{2} \mathrm{O}_{3}(\%)$ & $\mathrm{Fe}_{2} \mathrm{O}_{3}(\%)$ & $\mathrm{CaCO}_{3}(\%)$ \\
\hline $\mathrm{OPC}$ & 19.66 & 4.71 & 62.74 & 0.12 & 0.56 & - & 3.26 & 2.2 \\
Clear Glass & 73.50 & 0.06 & 9.02 & 12.65 & 0.02 & 0.02 & 0.28 & - \\
Green Glass & 73.10 & 1.65 & 10.55 & 12.34 & 0.58 & 0.24 & 0.44 & - \\
\hline
\end{tabular}

Table 0. Potential composition of cement based on Bogue equations and Rietveld analysis

\begin{tabular}{cccc|ccccccc}
\hline \multicolumn{3}{c|}{ Bogue equations } & \multicolumn{7}{c}{ Rietveld Analysis } \\
\hline $\begin{array}{c}\mathbf{C}_{3} \mathbf{S} \\
(\%)\end{array}$ & $\begin{array}{c}\mathbf{C}_{\mathbf{2}} \mathbf{S} \\
(\mathbf{\%})\end{array}$ & $\begin{array}{c}\mathbf{C}_{3} \mathbf{A} \\
(\%)\end{array}$ & $\begin{array}{c}\mathbf{C}_{\mathbf{4}} \mathbf{A F} \\
(\%)\end{array}$ & $\begin{array}{c}\text { Alite } \\
(\%)\end{array}$ & $\begin{array}{c}\text { Belite } \\
(\%)\end{array}$ & $\begin{array}{c}\text { Aluminate } \\
(\%)\end{array}$ & $\begin{array}{c}\text { Ferrite } \\
(\%)\end{array}$ & $\begin{array}{c}\text { Lime } \\
(\%)\end{array}$ & $\begin{array}{c}\text { Calcite } \\
(\%)\end{array}$ & $\begin{array}{c}\text { Gypsum } \\
(\%)\end{array}$ \\
\hline 58 & 11 & 7 & 10 & 64.1 & 14.6 & 4.36 & 10.01 & 0.40 & 2.54 & 4.03 \\
\hline
\end{tabular}

\section{Glass Cullet}

Clear and green glass was used in this study because previous research results showed that

clear glass is the most commonly available type of glass and green glass has the highest pozzolanic reaction. Small impurities are added as coloring agent in glass production. These coloring agents change the glass composition and structure. The source of clear glass was waste window glass collected from recycling company at Kansas City, KS, and the source of green glass was bottle glass from the same bottle manufacturer and bottle type collected from recycling center in Manhattan, KS. The glass was washed and dried to remove any residues before crushing. After crushing to smaller than $1.18 \mathrm{~mm}$ (No. 16), glass particles were milled in a laboratory ball mill. After ball milling, the glass was wet-sieved using a sieve with $25 \mu \mathrm{m}$ openings and isopropanol.

257 In addition to single glass types and particle sizes, one combination of the two glass types, green 258 and glass, and one narrow size ranges, $0-25 \mu \mathrm{m}$, were used in this study. The chemical compositions of the glass powders used for this study are shown in Table 3, while Table 5 shows 
260 glass powder density and Blaine fineness. Glass powder and cement particle size distribution is

261 shown in Figure 2, demonstrating that the gradation of glass powder is very similar to the cement

262 gradation. Particle shape and texture of cement grain and glass particles was investigated by

263 scanning electronic microscopy (SEM), as shown in Figure 3.

Table 5. Density and Blaine surface area of cementitious materials

\begin{tabular}{lll}
\hline Materials & Density $\left(\mathbf{K g} / \mathbf{m}^{3}\right)$ & Blaine Surface Area $\left(\mathbf{m}^{2} / \mathbf{K g}\right)$ \\
\hline OPC & 3150 & 395 \\
Clear Glass $0-25 \mu \mathrm{m}$ & 2477 & 433 \\
Green Glass $0-25 \mu \mathrm{m}$ & 2501 & 476 \\
Green $0-25 \mu \mathrm{m}+$ Clear $0-25 \mu \mathrm{m}$ (Mix 2) & 2492 & 454.5 \\
\hline
\end{tabular}

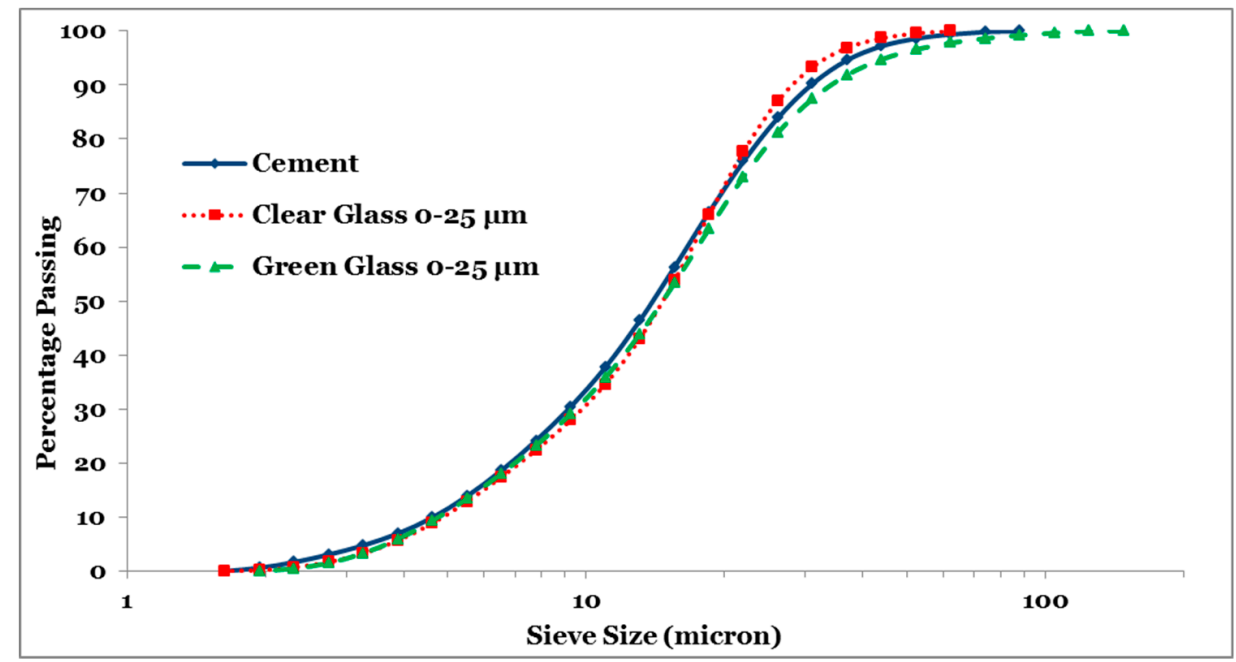



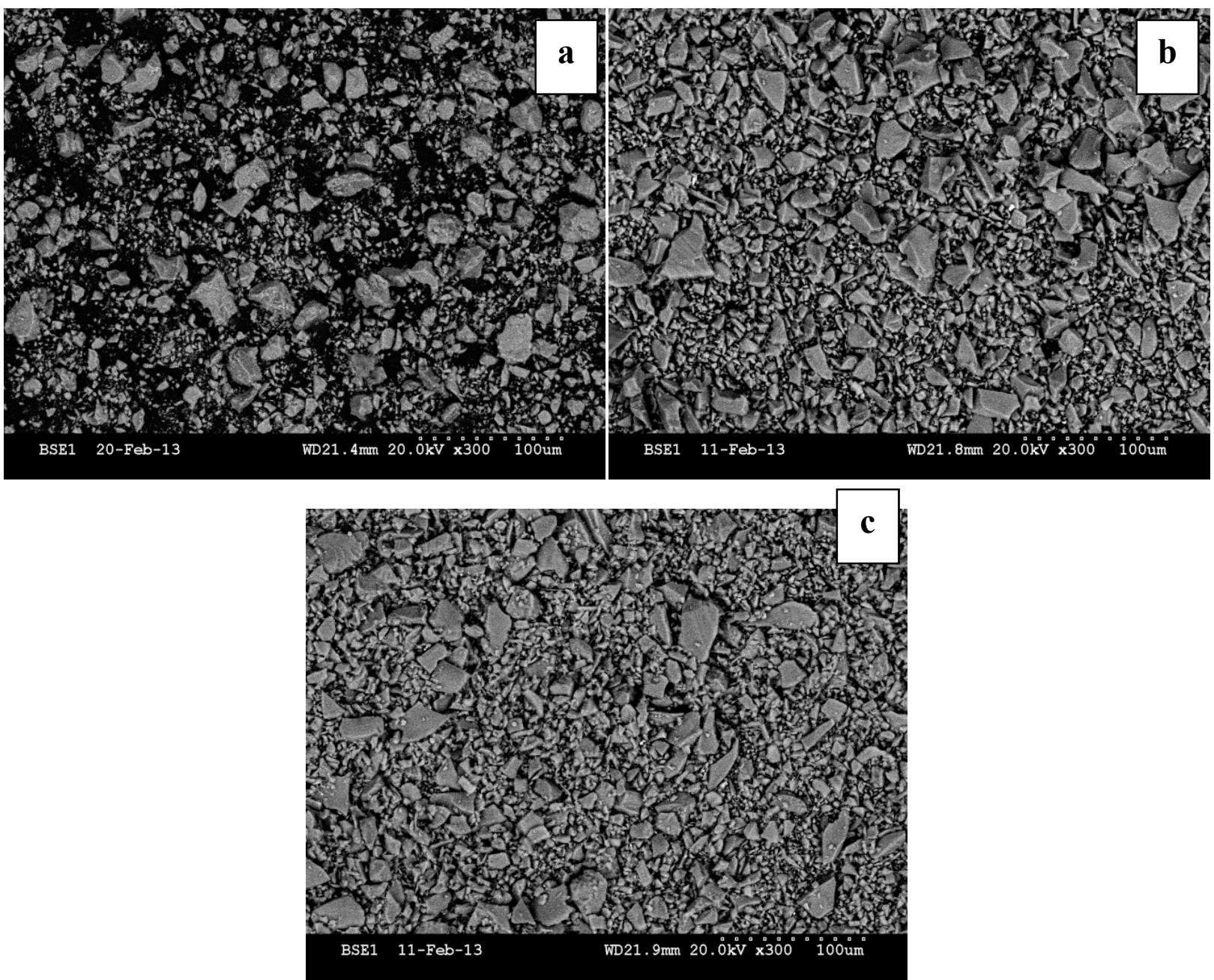

Figure 3. SEM Images; a. Cement grain, b. Clear glass 0-25 $\mu \mathrm{m}$, c. Green glass 0-25 $\mu \mathrm{m}$

\section{Methodology}

\section{Cement Paste Preparation}

Cement paste samples were made with a water-cementitious materials ratio $(\mathrm{w} / \mathrm{cm})$ of 0.35 , using a $25 \%$ replacement by mass of portland cement with individual clear or green glass powder as well as combined types and sizes of glass cullet, as recommended by other studies [49]. Samples were cured at $50^{\circ} \mathrm{C}$ in order to show hydration behavior at elevated temperature. Water and

277 cementitious materials were stirred at slow speed $(500 \mathrm{rpm})$ for three minutes, followed by two

278 minutes rest, and then high speed $(2000 \mathrm{rpm})$ for two minutes. Samples were pre-conditioned to 
the desired curing temperature before mixing. After mixing, paste samples for thermogravimetric analysis (TGA) were casted in a polystyrene vials with diameter of $17 \mathrm{~mm}$ and height of $50 \mathrm{~mm}$. Paste samples with or without the glass powder were wet-cured beginning at six hours after casting at three curing temperatures in a temperature-controlled chamber.

\section{Isothermal Calorimetry}

The hydration rate and total heat of hydration of cement were measured using an eightchannel isothermal calorimeter. Approximately $30 \mathrm{~g}$ of paste samples were placed in the sample containers, weighed, and placed into the calorimeter. The time between initial contact of water and cementitious materials and placing samples into the calorimeter was less than $15 \mathrm{~min}$ in all cases. The influence of glass type and curing temperature on hydration kinetics could be observed as the change in heat of hydration when the calorimetry results were normalized by the mass of dry portland cement used in the paste. This change in heat of hydration is likely from the dilution effect providing additional space for hydration product formation and glass powder providing nucleation platform for calcium silicate hydrate (C-S-H) and glass hydration $[79,80]$.

\section{Thermogravimetric Analysis (TGA)}

To study the pozzolanic reactivity of glass powder, the calcium hydroxide $(\mathrm{CH})$ content of cement paste samples was measured by the thermogravimetric analysis (TGA) using the approach outlined by Marsh [81]. Paste samples with or without the single particle and combined glass powder were wet-cured starting at six hours after casting at three curing temperatures. At 1, 7, 28, and 91 days after casting, hydration was stopped by solvent exchange with isopropanol. Paste samples were cut from the $17-\mathrm{mm}$ diameter samples into $2 \mathrm{~mm}$ thick discs and placed in isopropanol for seven days. The samples were then dried in a vacuum for at least four days. To minimize the risk of carbonation during casting, drying, and testing, high level of care was taken. 
302

303

304

305

306

307

308

309

310

Finally, 30-50 $\mathrm{mg}$ of dried paste samples were ground and heated at a rate of $20^{\circ} \mathrm{C} / \mathrm{min}$ to $1,000^{\circ} \mathrm{C}$ in nitrogen atmosphere.

\section{Hydration Modeling using $\mu$ ic}

In this section, two single particles and two types, as well as one blended glass particles and type of very finely ground glass are simulated by means of $\mu \mathrm{ic}$.

\section{Modeling of Cement Hydration}

In order to simulate glass cullet reactivity, the cement hydration needs to be modeled by means of $\mu$ ic. Modeling cement hydration means to fit reaction kinetics equation parameters. For this study, the reaction kinetics equation used for cement hydration as well as glass reactivity is the Avrami equation. The Avrami equation is a nucleation and growth model which was initially developed for metallic crystals. However, its S-shape is similar to the typical shape of cement hydration. Its implicity also helps make it one of the most popular reaction kinetics equations used for modeling cement hydration [6]. The Avrami equation can be expressed as Eq. (6) [82]:

$-\ln (1-\alpha)=\mathrm{ktn}$

Eq. (6)

where $\alpha$ is cement degree of hydration, $t$ is elapsed time from initial contact of water and cement, and $\mathrm{k}$ and $\mathrm{n}$ are Avrami parameters which depend on reaction rate and how crystals grow, respectively. The Avrami constant $\mathrm{n}$ is a function of three additional parameters as shown in Eq. (7):

$\mathrm{n}=(\mathrm{P} / \mathrm{S})+\mathrm{Q}$

Eq. (7)

where $\mathrm{P}$ is related to dimensions of products growths and can be 1, 2, or 3 for one-, two-, or three-dimensional growth, respectively. Parameter S is 1 for interface controlled and 2 for 
323 diffusion controlled mechanisms. Q is a function of rate of nucleation and can be 1 for continuous 324 nucleation and 0 for only initial nucleation [69]. Respectively selecting 3, 1, and 1 for P, S, and Q, 325 the value of $\mathrm{n}$ will be 4 for this study. Thus, the objective of modeling cement hydration is to find 326 the Avrami parameter $\mathrm{k}$ by fitting degree of hydration results obtained from $\mu$ ic to those obtained 327 from isothermal calorimetry. These values were used as fixed inputs for the next step of the 328 modeling process: modeling glass cullet.

The modeling in this study is done for three main compounds of cement, namely $\mathrm{C}_{3} \mathrm{~S}, \mathrm{C}_{2} \mathrm{~S}$, and $\mathrm{C}_{3} \mathrm{~A}$, to attain more descriptive results. Having very complicated hydration products and known to be rather slow reacting, $\mathrm{C}_{4} \mathrm{AF}$ has not been modeled in this study. Additionally, cement hydration and glass reactivity are simulated only at $50^{\circ} \mathrm{C}$ because previous experimental results showed that reaction rate of cement and pozzolanic reaction of glass cullet are more pronounced at $50^{\circ} \mathrm{C}$ compared to $10^{\circ} \mathrm{C}$ and $23^{\circ} \mathrm{C}[83]$.

\section{Step 1 - Initial Settings}

$\mu$ ic reads XML files that assign the hydration rate parameters and other inputs to the modeling engine. These XML input files can be created by a graphical user interface program or developed manually. From "File" tab in the command bar of the $\mu$ ic interface, "Load XML File" or "Create New Reactor" is selected. In this window the name of reactor, size of virtual paste cube, hydration time step, and some other initial settings such as pixel sizes and background color are determined. For this study, the size of the virtual paste cube is set to be a $100 \times 100 \times 100$ voxel cube. Figure 4 shows a screen shot of the Reactor window. 


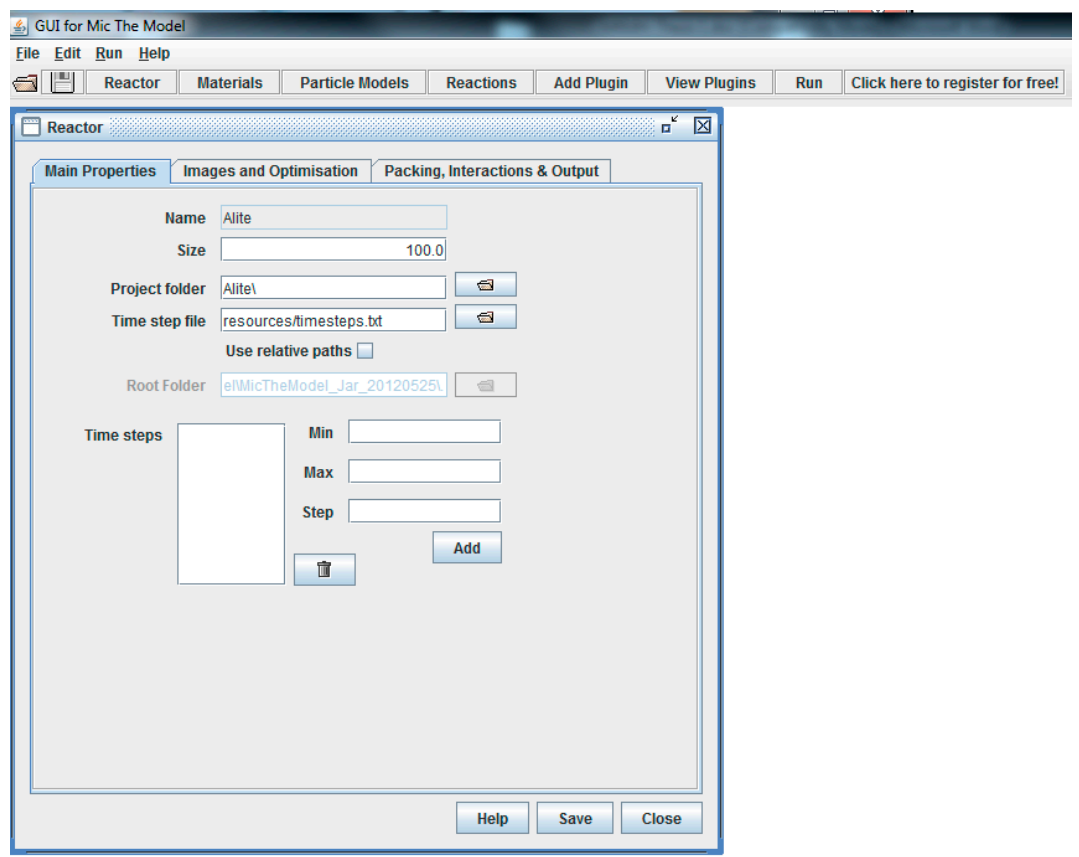

Figure 4. Reactor window in $\mu$ ic

345

Table 0. Properties of all materials used for cement hydration modeling in $\mu$ ic

\begin{tabular}{lcccc}
\hline Name & Density & Initial fraction & Diffusivity & Color \\
\hline Alite & 3.21 & 0.2832 & 0.04 & \\
Belite & 3.28 & 0.0646 & 0.04 & \\
Aluminate & 3.03 & 0.0193 & 0.04 & \\
C-S-H & 2.00 & 0.0 & 0.04 & \\
CH & 2.20 & 0.0 & 0.04 & \\
Ettringite & 2.00 & 0.0 & 0.04 & \\
\hline
\end{tabular}

Clicking on the "Materials" tab, a new window is opened in which all constituents used for modeling are defined. The constituents and properties used for cement hydration modeling are summarized in Table 6. Initial fractions of some constituents are volume percentages of those constituents, and have been calculated through volumetric stoichiometry. Figure 5 also shows the Materials window in $\mu$ ic. 




357 gradation, as well as layers of hydration products. Gradation results of different constituents are

358 obtained by laser particle size distribution. For example, the layers of alite are alite (unreacted core

$359 \mathrm{C}_{3} \mathrm{~S}$ ) and $\mathrm{C}-\mathrm{S}-\mathrm{H}$ layer formed on the $\mathrm{C}_{3} \mathrm{~S}$ particles. Table 7 lists the reactants and corresponding 360 products layers. Figure 6 shows a preview of Particle Models window.

Table 7. List of reactants and corresponding products used for modeling in $\mu$ ic

\begin{tabular}{lc}
\hline Reactant & Products Layer \\
\hline Alite & Alite + C-S-H \\
Belite & Belite + C-S-H \\
Aluminate & Aluminate + Ettringite \\
\hline
\end{tabular}




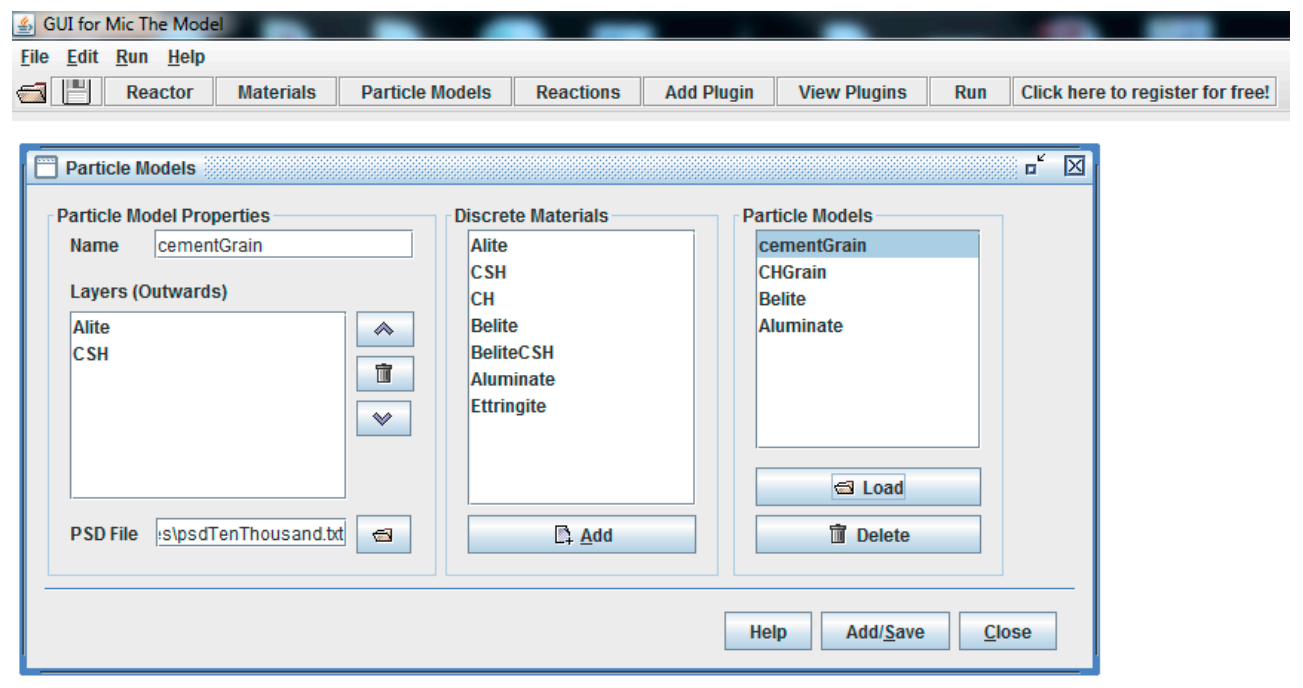

Step 4 - Reactions

A critical step in simulation in $\mu$ ic is to define reactions of different phases through mathematical equations. Hydrations of different phases of cement are typically expressed as mass equations, as previously shown in Eq. (1), Eq. (2), and Eq. (3).Since cement hydration is modeled in a paste cube and all fractions and calculations are volumetric-based, reactions equations should also be converted to volumetric equations. These conversions are done through stoichiometry and by assigning densities. Material densities used in this study are shown in Table 8. Equations (8), (9), and (10) show the volumetric equations for the reaction of different phases:

"Reactions" window allows users to define and customize different hydration equations. In this study, hydration equations (8), (9), and (10) are plugged into $\mu$ ic. As shown in Figure 7. 


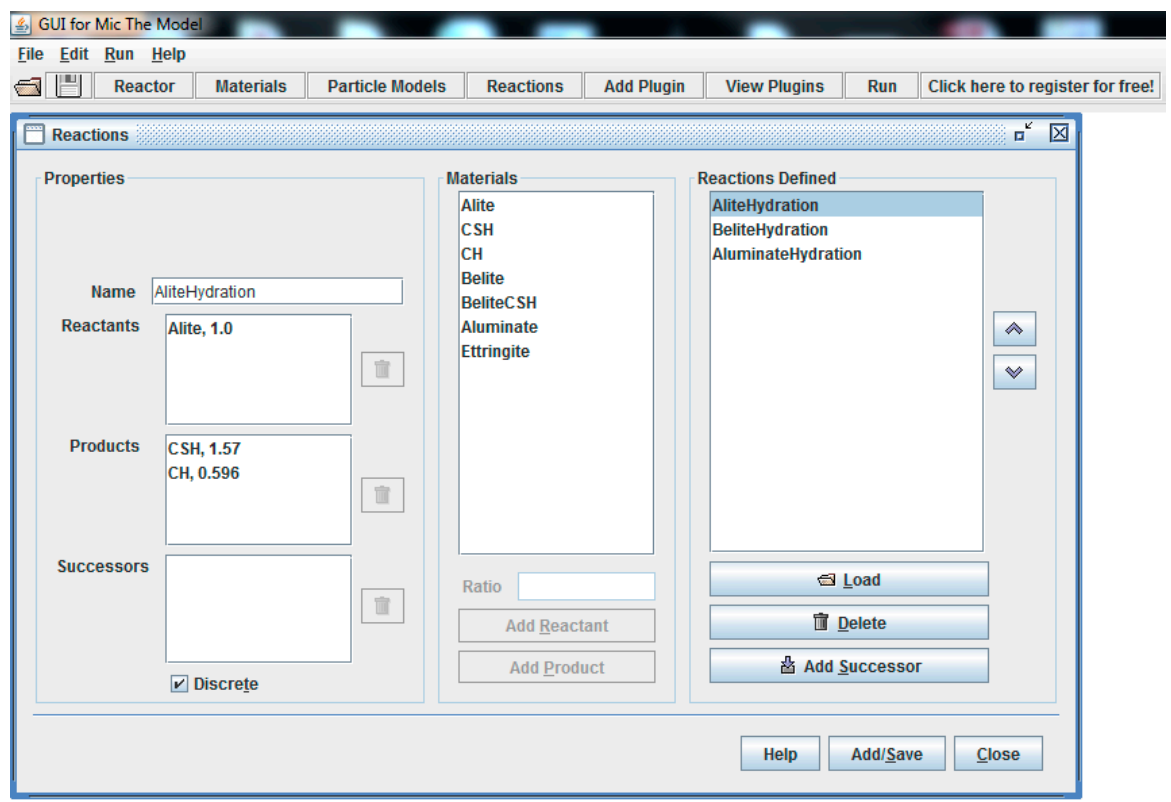
model depending on objective of the modeling, or add new customized plugins in Java to the list. Avrami model is selected.

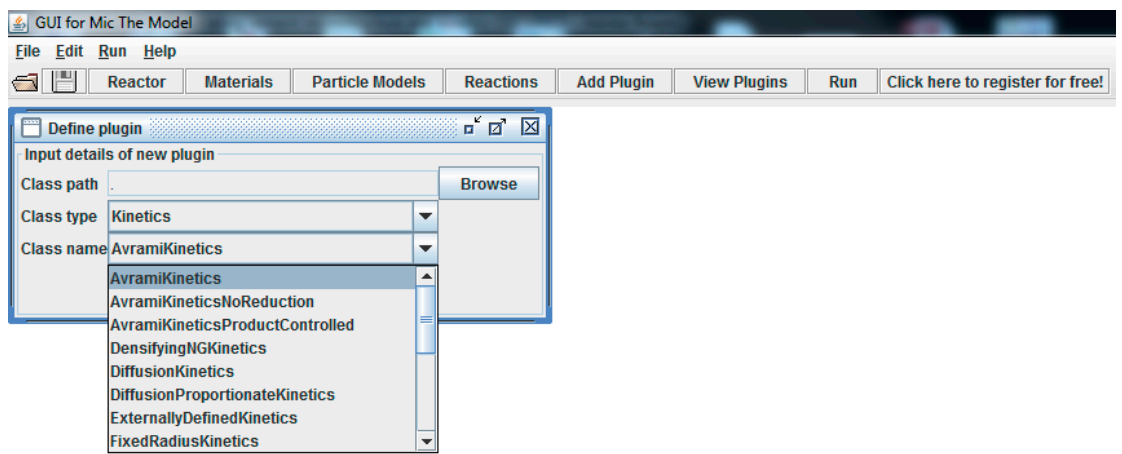



order of implementation of kinetics (set to one for all, as all reactions happen simultaneously), and types of reactions and reactants are determined. Figure 9 shows a set Avrami model for alite hydration.

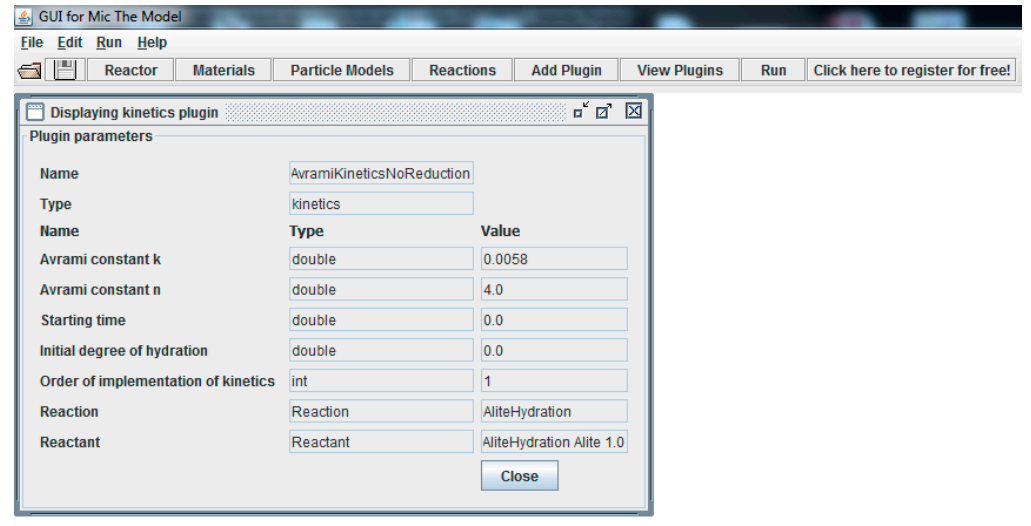

This window allows users to control all determined plugins.

After saving the project, users can run the model. Once the model runs, a folder in the name of project is automatically created which contains a cross section of simulated hydration at each time steps (Figure 10), as well as an excel file that gives the degree of hydration and changes in volume of all constituents at each time steps. The black pixels shown in Figure 10 are porosity. 
400

401

402

403

404

405

406

407

408

409

410

411

412

\section{Modeling of Glass Cullet Reactivity}

\section{Single type and particle size}

Modeling of pozzolanic reaction of two glass types (i.e. clear and green) and one single particle size $(<25 \mu \mathrm{m})$ of finely ground glass followed the same basic modeling steps as those explained for cement hydration modeling, with only a few alterations. Clear glass smaller than 25 $\mu \mathrm{m}$, green glass smaller than $25 \mu \mathrm{m}$, and pozzolanic C-S-H were added to the previous constituents, but simulated through separate models to determine the reaction rate parameters to use for each material by itself. Table 8 shows the properties of the individual types of glass in $\mu$ ic.

Table 0. Properties of glass particles used for pozzolanic reaction modeling in $\mu$ ic

\begin{tabular}{lcccc}
\hline Name & Density & Initial fraction & Diffusivity & Color \\
\hline Clear $<25 \mu \mathrm{m}$ & 2.48 & 0.1455 & 0.0 & \\
Green $<25 \mu \mathrm{m}$ & 2.50 & 0.1455 & 0.0 & \\
Pozzolanic C-S-H & 2.00 & 0.0 & 0.04 & \\
\hline
\end{tabular}

In the "Particle Models" window, gradations of glass particles obtained from laser particle size distribution device were defined. Reactants and products layers on glass particles were also determined. Table 9 lists the glass reactants and corresponding hydration products. 

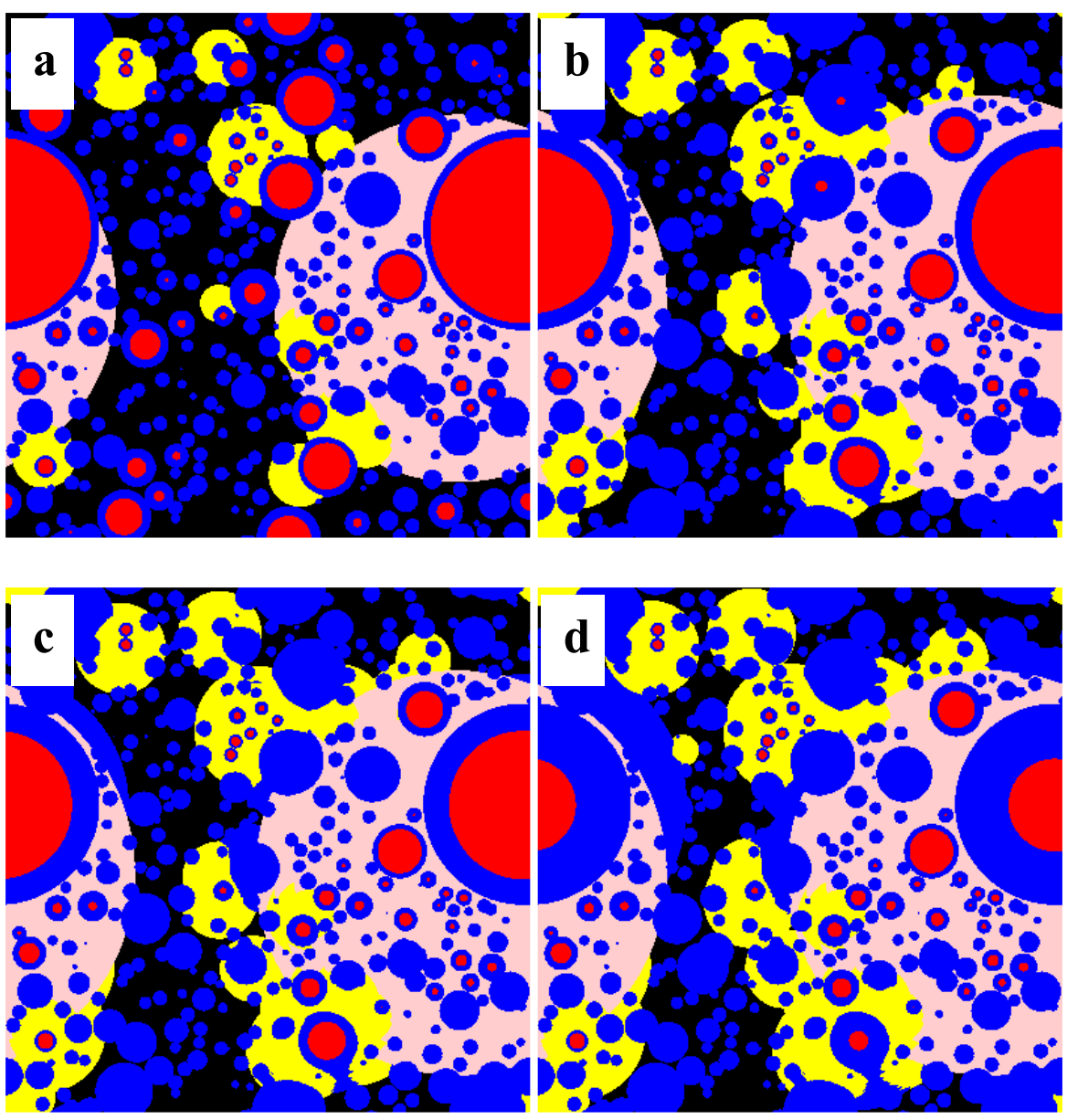

Figure 10. Cross sections of simulated cement hydration at $50^{\circ} \mathrm{C}$ : a. 1 day, b. 28 days, c. 91 days, and d. 365 days

Table 0 . List of glass reactants and corresponding products used for modeling in $\mu$ ic

\begin{tabular}{lc}
\hline Reactant & Products Layer \\
\hline Clear $<25 \mu \mathrm{m}$ & G025 + C-S-HG025 \\
Green $<25 \mu \mathrm{m}$ & GG025 + C-S-HGG025 \\
\hline
\end{tabular}
et al. [43] and is shown determine in Eq. (11): 
422

423

424

425

426

427

428

429

430

431

432

433

434

435

436

437

438

439

440

441

where $\mathrm{N}$ is shorthand for $\mathrm{Na}_{2} \mathrm{O}$. Using the material densities shown in Table 8 and the stoichiometric calculations from Eq. (11) give a volumetric-based equation shown in Eq. (12):

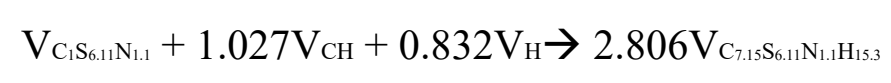

The last step for modeling the pozzolanic reactivity of glass cullet was to obtain the Avrami constants. These constants were attained through a trial-error process used in modeling to fit to the $\mathrm{CH}$ content calculated curve determined by TGA measurements.

\section{Combined glass types and particle sizes}

The process of the modeling Mix 2 was the same as that previously outlined for cement and single glass particles. To model combined glass types and sizes (Mix 2), the fit Avrami constants for cement, Clear glass smaller than $25 \mu \mathrm{m}$, and Green glass smaller than $25 \mu \mathrm{m}$ at $50^{\circ} \mathrm{C}$ obtained by modeling them in separate steps were used. The only difference between modeling Mix 2 and earlier materials is that the initial fractions of both Clear glass smaller than $25 \mu \mathrm{m}$ and Green glass smaller than $25 \mu \mathrm{m}$ are 0.07275 instead of 0.1455 (see Table 8).

\section{Results and Discussions}

\section{Avrami Constants for Cement}

The Avrami constants found from fitting the model degree of hydration to the degree of hydration found from isothermal calorimetry for three compounds of cement are shown in Table 10. Figure 11 shows the fit obtained from the modeling to the measured data. 
442 Table 10. Avrami constants of three phases obtained by $\mu$ ic

443

444

\begin{tabular}{lcc}
\hline \multirow{2}{*}{ Name } & \multicolumn{2}{c}{ Avrami Constants } \\
\cline { 2 - 3 } & $k$ & $n$ \\
\hline Alite & $5.8 \mathrm{E}-3$ & 4.0 \\
Belite & $3.3 \mathrm{E}-3$ & 4.0 \\
Aluminate & $7.0 \mathrm{E}-3$ & 4.0 \\
\hline
\end{tabular}

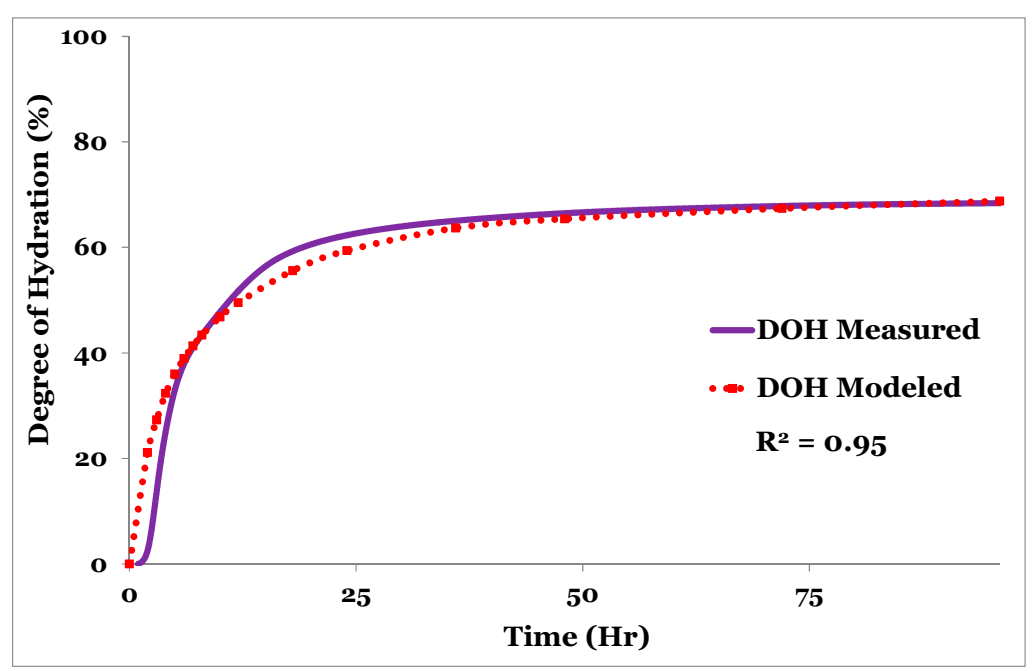

Figure 11. Fitting modeled to measured DOH results

\section{Avrami Constants of Single Glass Cullet}

Cross sections of simulated microstructures for cementitious systems containing green glass smaller than $25 \mu \mathrm{m}$ are shown in Figure 12. Following the same method discussed for modeling clear glass, the Avrami parameters for the green glass smaller than $25 \mu \mathrm{m}$ material were fit using the TGA measurements as shown in Figure 13. The Avrami parameters for the pozzolanic reactivity of Green glass smaller than $25 \mu$ m were found to be $\boldsymbol{k}=\mathbf{1 . 0 8 9 9 E}-\mathbf{5}$ and $\boldsymbol{n}=\mathbf{1 . 5}$. 

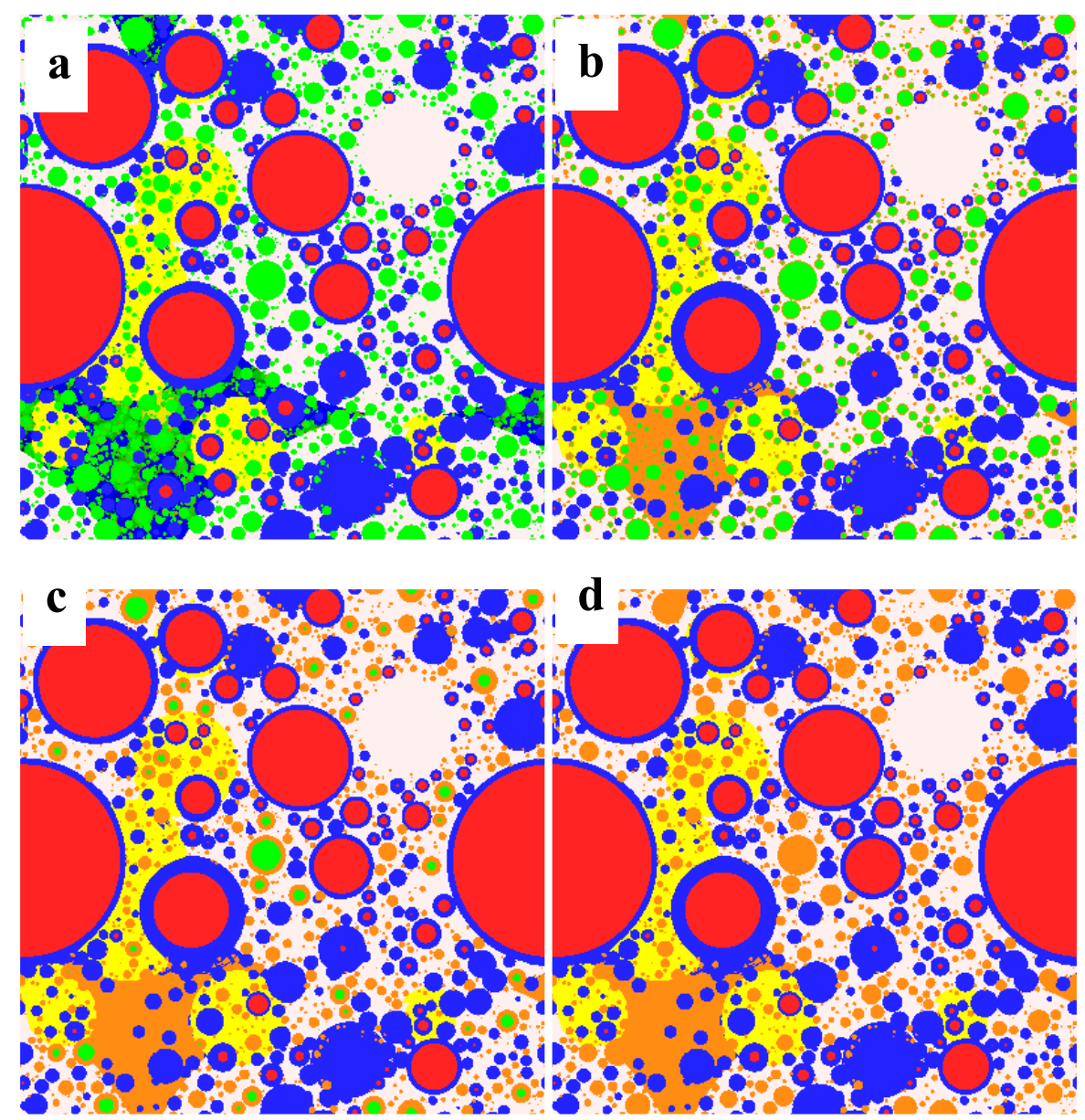

Figure 12. Cross sections of simulated pozzolanic reaction of Green glass $<25 \mu \mathrm{m}$ at $50^{\circ} \mathrm{C}:$ a. 1 day,

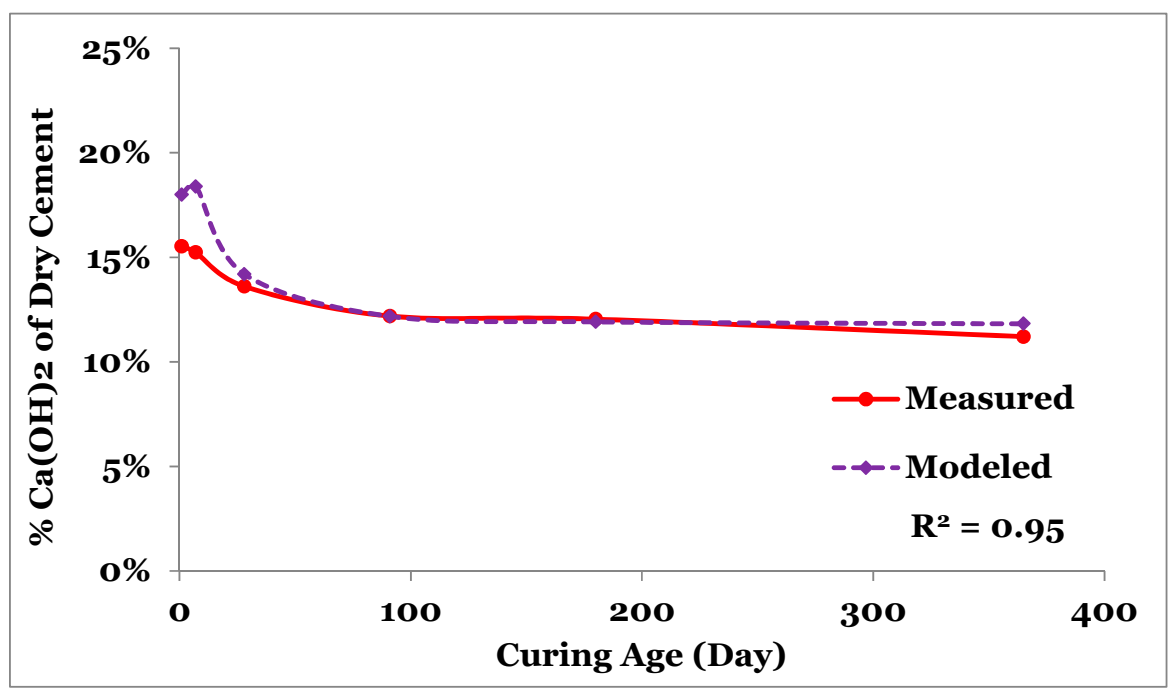

Figure 13. Fitting modeled to measured results of $\mathrm{CH}$ content for Green glass $<25 \mu \mathrm{m}$ at $50^{\circ} \mathrm{C}$ 
459

\section{Avrami Constants of Combined Glass Cullet}

Cross sections of simulated microstructures for cementitious systems Mix 2 are shown in
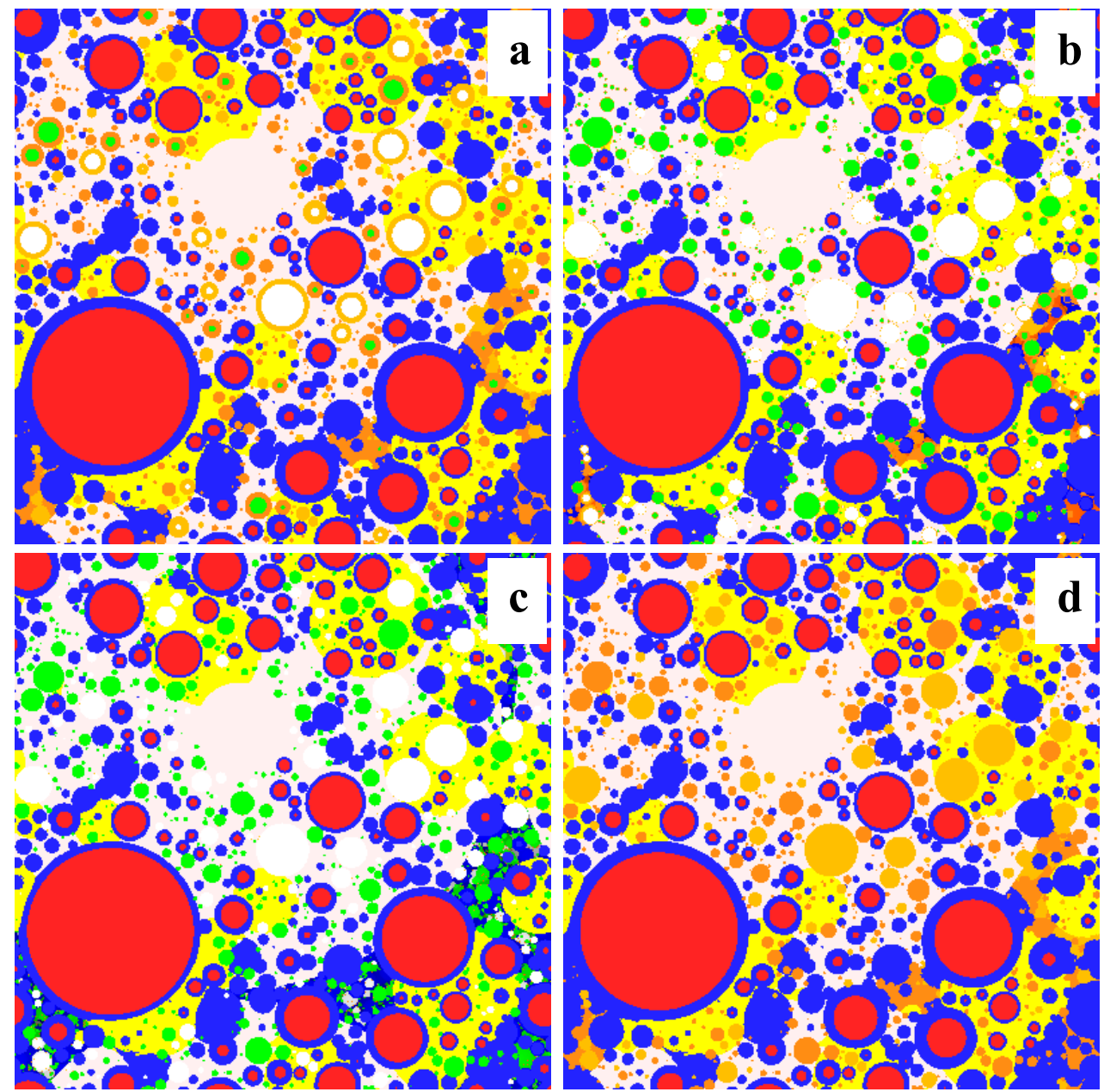

Figure 14. Cross sections of simulated pozzolanic reaction of $\mathrm{Mix} 2$ at $50^{\circ} \mathrm{C}:$ a. 1 day, b. 28 days, c.

91 days, and d. 365 days

The first interesting point is that the modeling of Mix 2 pozzolanic reactivity was in well agreement with the calculated $\mathrm{CH}$ content obtained from the modeling of single particles $(\mathrm{R} 2=0.99)$ as shown in Figure 15. Results also showed that simulation for Mix 2 was not satisfactory and the differences between measured and modeled values are significant. In other words, the effect of particle sizes of on glass cullet pozzolanic reactivity could not be accounted for through linear addition as expected to be obtained by microstructural modeling. This 
473 discrepancy might be caused by some errors in Avrami constants attained in modeling of cement 474 and single glass particles. Another possible explanation for inaccurate modeling is the effect of 475 elevated curing temperatures on reactivity and mechanical properties of cementitious systems 476 containing Mix 2. As explained earlier, Mix 2 physical properties do not follow the linear-addition 477 behavior. In other word, elevated curing temperatures is an important parameter not only in 478 reactivity and mechanical properties of concrete containing mixed types and sizes of glass, but 479 also in microstructural modeling.

480

481

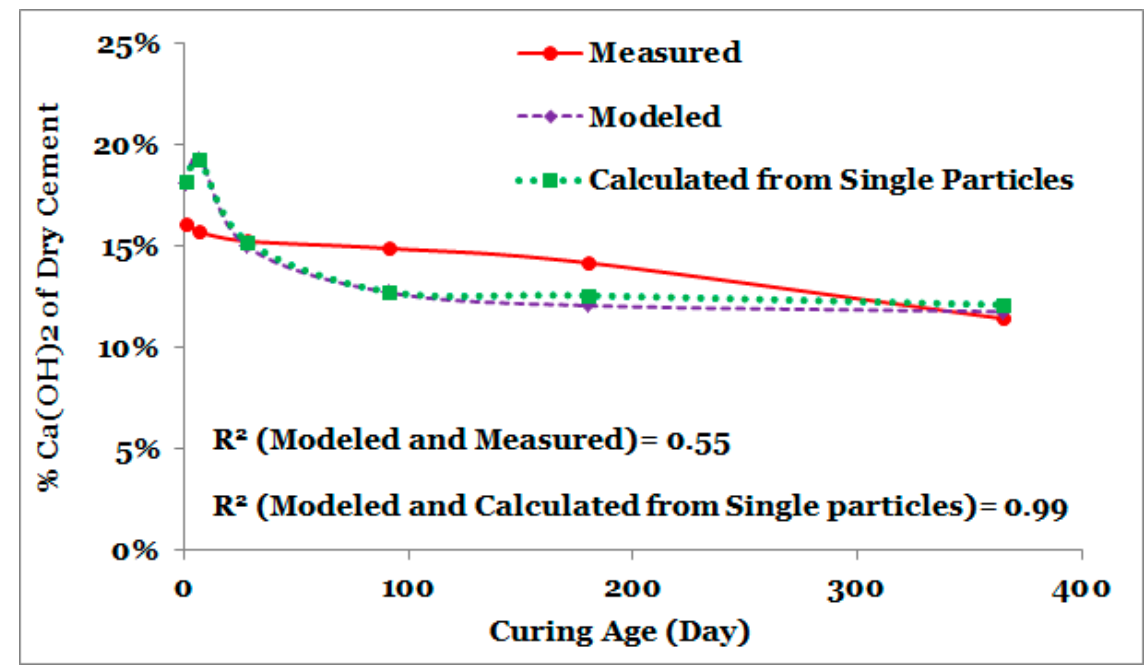

Figure 15. Fitting modeled to measured results of $\mathrm{CH}$ content for $\mathrm{Mix} 2$ at $50^{\circ} \mathrm{C}$

\section{Conclusion}

The objective of this study was to microstructurally model cement hydration and cementitious systems containing single glass types and sizes and combined glass types and sizes. In order to achieve these goals, a newly developed modeling platform called " $\mu$ ic" was used. Modeling outputs were fitted to the results of experimental studies. Some minor errors were seen in modeling cement and glass particles, especially at early ages. Despite acceptable fits of single type and size of glass cullet, microstructural modeling could not verify that the effect of particle size distribution on pozzolanicity (i.e. combined glass types and sizes) of glass powder is linear. 
490 This inaccuracy can be attributed not only to some inherent limitations of microstructural modeling

491 such as limited knowledge about mechanisms of hydration kinetics, but also to accumulation of

492 minor errors in earlier steps of modeling, effects of some important factors such as curing 493 temperatures and gradation, and accuracy of reaction equations. It can be recommended that a 494 comprehensive stoichiometry study is performed on pozzolanic reaction of glass cullet to obtain a 495 precise equation which can be used in microstructural modeling platforms like $\mu$ ic.

\section{Acknowledgment}

This work has been funded by the National Science Foundation (CMMI-1032636). The

498 author would like to acknowledge Ash Grove Cement Company for performing XRF 499 measurements and measuring surface area and density of materials, and Kyle A. Riding for his 500 valuable advices. 
502

503

504

505

506

507

508

509

510

511

512

513

514

515

516

517

518

519

520

521

522

523

524

\section{References}

[1] United Nation Environmental Program (UNEP) (2010). Greening Cement Production has a Big Role to Play in Reducing Greenhouse Gas Emissions. http://na.unep.net/geas/getUNEPPageWithArticleIDScript.php?article id=57 (downloaded on March 14, 2014)

[2] Van Oss, H. G. (2011). USGS Mineral Program Cement Report. United States Geological Survey (USGS) Report, pp. 38-39.

[3] Lin, F., and Meyer C. (2009). Hydration kinetics modeling of Portland cement considering the effects of curing temperature and applied pressure, Cement and Concrete Research, vol. 39, pp. 255-265.

[4] Kirby, D. M., and Biernacki, J. J. (2012). The effect of water-to-cement ratio on the hydration kinetics of tricalcium silicate cements: Testing the two-step hydration hypothesis, Cement and Concrete Research, vol. 42, pp. 1147-1156.

[5] Kosmatka, S. H., Kerkhoff, B., and Panarese, W. C. (2003). Design and Control of Concrete Mixtures, Portland Cement Association, $14^{\text {th }}$ Edition, USA, pp. 360.

[6] Bishnoi, S. (2008). Vector Modelling of Hydrating Cement Microstructure and Kinetics, Doctoral Thesis, Swiss Federal Institute of Technology in Lausanne, Laboratory of Materials of Construction, pp. 166.

[7] Bullard, J. W., Jennings, H. M. , Livingston, R. A., Nonat, A., Scherer, G. W., Schweitzer J. S., Scrivener, K. L., and Thomas, J. J. (2011). Mechanisms of cement hydration, Cement and Concrete Research, vol. 41, pp. 1208-1223.

[8] Stein, H. N., and Stevels J. M. (1964). Influence of silica on the hydration of $3 \mathrm{CaO}, \mathrm{SiO}_{2}$, J. Appl. Chem., vol. 14, vol. 338-346. 
525 [9] Juilland, P., Gallucci, E., Flatt, R., and Scrivener, K. (2010). Dissolution theory applied to 526 the induction period in alite hydration, Cement and Concrete Research, vol. 40, pp. 831$527 \quad 844$.

528 [10] Gartner, E. M., and Gaidis, J. M. (1989). Hydration mechanisms, I, in: J. Skalny (Ed.), 529 Materials Science of Concrete, Vol. 1, American Ceramic Society, Westerville, OH, pp. $530 \quad 95-125$.

531 [11] Garrault, S., and Nonat, A. (2001). Hydrated layer formation on tricalcium and dicalcium 532 silicate surfaces: experimental study and numerical simulations, Langmuir, vol. 17, pp. 8131-8138.

534 [12] Garrault-Gauffinet, S., and Nonat, A. (1999). Experimental investigation of calcium silicate hydrate (C-S-H) nucleation, J. Cryst. Growth, vol. 200, pp. 565-574.

[13] Damidot, D., Nonat, A., and Barret P. (1990). Kinetics of tricalcium silicate hydration in diluted suspensions by microcalorimetric measurements, J. Am. Ceram. Soc., vol. 73(11), pp. 3319-3322.

[14] Arvidson, R. S., Fischer, C., and Luttge, A. (2009). Resolution of crystal dissolution and growth processes at multiple scales, Geochim. Cosmochim. Acta, vol. 72 (12), A34.

541 [15] Damidot, D., Bellmann, F., Möser, B., and Sovoidnich, T. (2007). Calculation of the 542 dissolution rate of tricalcium silicate in several electrolyte compositions, Cement WapnoBeton, vol. 12/74 (2), pp. 57-67.

544 [16] Ménétrier, D., Jawed, I., Sun, T. S., and Skalny J. (1979). ESCA and SEM studies on early $\mathrm{C}_{3} \mathrm{~S}$ hydration, Cem. Concr. Res., vol. 9, pp. 473-482.

546 [17] Tadros, M. E., Skalny, J., Kalyoncu, R. S. (1976). Early hydration of tricalcium silicate, Journal of the American Ceramic Society, vol. 59 (7-8), pp. 344-347. 
548 [18] Young, J. F., Tong, H. S., and Berger, R. L. (1977). Compositions of solutions in contact 549 with hydrating tricalcium silicate pastes, Journal of the American Ceramic Society, vol. 60 550 (5-6), pp. 193-198.

551

552

553

554

555

556

557

558

559

560

561

562

563

564

565

566

567

568

569

570

571

[19] Damidot, D., and Nonat, A. (1994). $\mathrm{C}_{3} \mathrm{~S}$ hydration in diluted and stirred suspensions: (I) study of the two kinetic steps, Advances in Cement Research, vol. 6 (21), pp. 27-35.

[20] Barret, P., and Ménétrier, D. (1980). Filter dissolution of $\mathrm{C}_{3} \mathrm{~S}$ as a function of lime concentration in a limited amount of lime water, Cement and Concrete Research, vol. 10, pp. 521-534.

[21] Kondo, R., and Ueda, S. (1968). Kinetics of hydration of cements, Proceedings of the $5^{\text {th }}$ international symposium on chemistry of cement, Tokyo, pp. 203-248.

[22] Pommersheim, J. M., and Clifton, J. R. (1979). Mathematical modeling of tricalcium silicate hydration, Cement and Concrete Research, Vol. 9, pp. 765-770.

[23] Gartner, E. M., and Gaidis, J. M. (1989). Hydration mechanisms, I, in: J.P. Skalny (Ed.), The Materials Science of Concrete, I, American Ceramic Society, pp. 95-125.

[24] Jennings, H. M., and Pratt, P. L. (1979). An experimental argument for the existence of a protective membrane surrounding Portland cement during the induction period, Cement and Concrete Research, vol. 9, pp. 501-506.

[25] Xie, T., and Biernacki, J. J. (2011). The origins and evolution of cement hydration models, Comp. Concr., vol. 8(6), pp. 647-675.

[26] Garrault, S., Behr, T., and Nonat, A. (2006). Formation of the C-S-H layer during early hydration of tricalcium silicate grains with different sizes, Journal of Physical Chemistry, Vol. 110, pp. 270-275.

[27] Bishnoi, S., and Scrivener, K. L. (2009). $\mu$ ic: a new platform for modeling the hydration of cements, Cem. Concr. Res., vol. 39(4), pp. 266-274. 
572 [28] Bishnoi, S., and Scrivener, K. L. (2009). Studying nucleation and growth kinetics of alite 573 hydration using $\mu$ ic, Cem. Concr. Res., vol. 39(10), pp. 849-860.

574 [29] Van Breugel, K. (1991). Simulation of hydration and formation of structure in hardening 575 cement-based materials, PhD Thesis, Delft University of Technology, The Netherlands.

576 [30] Danielson, U. (1962). Heat of hydration of cement as affected bywater-cement ratio, 577 Paper IV-S7, Proceedings of the 4th International Symposium on the Chemistry of Cement, $578 \quad$ Washington DC, USA, pp. 519-526.

579 [31] Taplin, J. H. (1969). A method for following hydration reaction in Portland cement paste, $580 \quad$ Australian Journal of Applied Sciences, vol. 10, pp. 329-345.

581 [32] Knudsen, T. (1982). Modeling hydration of portland cement - the effect of particle size 582 distribution, in: Young, J. F. (Ed.). Characterization and performance prediction of cement and concrete, United Engineering Trustees, Inc., New Hampshire, USA, pp. 125-150.

584

585

586

587

588

589

590

591

592

593

594

[33] Frigione, G., and Marra, S. (1976). Relationship between particle size distribution and compressive strength in Portland cement, Cement and Concrete Research, vol. 6(1), pp. $113-127$.

[34] Bezjak, A. (1986). An extension of the dispersion model for the hydration of Portland cement, Cement and Concrete Research, vol. 16 (2), pp. 260-264.

[35] Lerch, W., and Ford, C. L. (1948). Long-term study of cement performance in concrete: chapter 3, Chemical and physical tests of the cements, ACI Journal, vol. 19(8), pp. 745795.

[36] Escalante-Garcia, J. I. (2003). Nonevaporable water from neat OPC and replacement materials in composite cements hydrated at different temperatures, Cement and Concrete Research, vol. 33(11), pp. 1883-1888. 
595 [37] Bentur, A., Berger, R. L., Kung, J. H., Milestone, N. B., and Young J. F. (1979), 596 Structural properties of calcium silicate pastes: II, effect of the curing temperature, Journal 597 of the American Ceramic Society, vol. 62(7-8), pp. 362-366.

598

[38] Worrell, E., Price, L., Martin, N., Hendriks, C., and Meida, L. O. (2001). Carbon dioxide 599 emissions from the global cement industry, Annual Review of Energy and the 600 Environment, vol. 26, pp. 303-329.

601 [39] Lothenbach, B., Scrivener, K., Hooton, R. D. (2011). Supplementary cementitious 602 materials, Cement and Concrete Research, vol. 41, pp. 1244-1256.

603

604

605

606

607

608

609

610

611

612

613

614

615

616

617

618

[40] United States Environmental Protection Agency (EPA) (2010). Municipal solid waste in the United States: 2009 Facts and Figures. Report No. EPA530-R-10-012.

[41] Shao, Y., Lefort, T., Moras, S., and Rodriguez, D. (2000). Studies on Concrete Containing Ground Waste Glass. Cement and Concrete Research, vol. 30(1), pp. 91-100.

[42] Shi, C., and Zheng, K. (2007). A Review on the Use of Waste Glasses in the Production of Cement and Concrete. Resources, Conservation and Recycling, vol. 52(2), pp. 234-247.

[43] Saeed, H. A., Ebead, U. A., Tagnit-Hamou, A., and Neale, K. W. (2011). Stoichiometric study of activated glass powder hydration. Advances in Cement Research, vol. 24(2), pp. 91-101.

[44] Dyer, T. D., and Dhir, R. K. (2001). Chemical Reactions of Glass Cullet Used as Cement Component. Journal of Material of Civil Engineering, vol. 13(6), pp. 412-417.

[45] Shayan, A., and Xu, A. (2004). Value-added Utilization of Waste Glass in Concrete. Cement and Concrete Research, vol. 34(1), pp. 81-89.

[46] Shayan, A., and Xu, A. (2006). Performance of Glass Powder as a Pozzolanic Material in Concrete: A Field Trial on Concrete Slabs. Cement and Concrete Research, vol. 36(3), pp. 457-468. 
619 [47] Pereira-de-Oliveira, L. A., Castro-Gomes, J. P., and Santos, P. M. S. (2012). The Potential 620 Pozzolanic Activity of Glass and Red-clay Ceramic Waste as Cement Mortars 621 Components. Construction and Building Material, vol. 31, pp. 197-203

622 [48] Schwarz, N., and Neithalath, N. (2008). Influence of a fine glass powder on cement 623 hydration: Comparison to fly ash and modeling the degree of hydration. Cement and 624 Concrete Research, vol. 38, pp. 429-436

625

626

627

[49] Tagnit-Hamou, A., and Bengougam, A. (2012). The Use of Glass Powder as Supplementary Cementitious Material. Concrete International, vol. 34(3), pp. 56.

[50] Shi, C., Wu, Y., Riefler, C., and Wang, H. (2005). Characteristics and Pozzolanic Reactivity of Glass Powders. Cement and Concrete Research, vol. 35(5), pp. 987-993.

[51] Nassar, R., and Soroushian, P. (2011). Field Investigation of Concrete Incorporating Milled waste Glass, Journal of Solid Waste Technology and Management, vol. 37(4), pp. 307-319.

[52] Bajad, M. N., Modhera, C. D., and Desai, A. K. (2011). Effect of Glass on Strength of Concrete Subjected to Sulphate Attack, International Journal of Civil Engineering Research and Development, vol. 1(2). pp. 1-13.

[53] Meena, A., and Singh, R. (2012). Comparative Study of Waste Glass Powder as Pozzolanic Material in Concrete, Bachelor Thesis, Department of Civil engineering, National Institute of Technology, Rourkela, India, pp. 46.

[54] Kou, S. C., and Xing, F. (2012). The Effect of Recycled Glass Powder and Reject Fly ash on the Mechanical Properties of fiber-reinforced Ultralight Performance Concrete, Advances in Material science and Engineering, pp. 8. 
641 [55] Federico, L. (2013). Waste Glass - A Supplementary Cementitious Material, Ph.D. 642 Dissertation, Department of Civil engineering, McMaster University, Hamilton, Ontario, $643 \quad$ Canada, pp. 99.

644 [56] Xu, W., and Chen, H. (2012). Microstructural modelling of cement-based materials via 645 random packing of three-dimensional ellipsoidal particles. Procedia Engineering, vol. 27, $646 \quad$ pp. $332-340$.

647 [57] Gallucci, E., Mathur, P., and Scrivener, K. (2010). Microstructural development of early 648 age hydration shells around cement grains, Cement and Concrete Research, vol. 40, pp. 4$649 \quad 13$.

650 [58] Thomas, J. J., Biernacki, J. J., Bullard, J. W., Bishnoi, S., Dolado, J. S., Scherer, G. W., 651 and Luttge, A. (2011). Modeling and simulation of cement hydration kinetics and 652 microstructure development. Cement and Concrete Research, vol. 41, pp. 1257-1278.

[59] Diamond, S. (2004). The microstructure of cement paste and concrete - a visual primer, Cement \& Concrete Composites, vol. 26, pp. 919-933.

655 [60] Merzouki, T., Bouasker, M., Khalifa, N. E. H., and Mounanga, P. (2013). Contribution 656 to the modeling of hydration and chemical shrinkage of slag-blended cement at early age, 657 Construction and Building Materials, vol. 44, pp. 368-380.

658 [61] Bentz, D. P. (2008). Virtual Pervious Concrete: Microstructure, Percolation, and 659 Permeability, ACI Materials Journal, vol. 105(3), pp. 297-301.

660 [62] Bentz, D. P. (2000). Influence of silica fume on diffusivity in cement-based materials II. 661 Multi-scale modeling of concrete diffusivity, Cement and Concrete Research, vol. 30, pp. $662 \quad 1121-1129$.

663 [63] Roy, D. M. (1993). Concrete microstructure, Strategic Highway Research Program 664 (SHRP), National Research Council, Washington, DC 1993. 
665

666

667

668

669

670

671

672

673

674

675

676

677

678

679

680

681

682

683

684

685

686

687

688

[64] Thomas, J. J., Biernacki, J. J., Bullard, J. W., Bishnoi, S., Dolado, J. S., Scherer, G. W., and Luttge, A. (2011). Modeling and simulation of cement hydration kinetics and microstructure development. Cement and Concrete Research, vol. 41, pp. 1257-1278.

[65] Pommersheim, J. M., and Clifton, J. R. (1979). Mathematical modeling of tricalcium silicate hydration, Cem. Concr. Res, vol. 9, pp. 765-770.

[66] Parrot in 2796: Parrot, L. J., and Killoh, D. C. (1984). Prediction of cement hydration, Br. Ceram. Proc., vol. 35, pp. 41-53.

[67] Tomosawa, F. (1997). Development of a Kinetic Model for Hydration of Cement, in: H. Justnes (Ed.), Proceedings of the Tenth International Congress on the Chemistry of Cement, Göteburg, Sweden.

[68] Tenoutasse, N., and De Donder, A. (1970). The kinetics and mechanism of hydration of tricalcium silicate, Silicates Ind., vol. 35, pp. 301-307.

[69] Brown, P. W., Pommersheim, J. M., and Frohnsdorff, G. (1985). A kinetic model for the hydration of tricalcium silicate, Cem. Concr. Res., vol. 15, pp. 35-41.

[70] Gartner in 2796: Gartner, E. M., and Gaidis, J. M. (1989). Hydration Mechanisms, I, in: J.P. Skalny (Ed.), Materials Science of Concrete, American Ceramic Society, Westerville, OH, pp. 95-125.

[71] Cahn, J. W. (1956). The kinetics of grain boundary nucleated reactions, Acta Metall. vol. 4, pp. 449-459.

[72] Thomas, J. J. (2007). A new approach to modeling the nucleation and growth kinetics of tricalcium silicate hydration, J. Am. Ceram. Soc., vol. 90, pp. 3282-3288.

[73] Frohnsdorff, G. J. C., Freyer, W. G., and Johnson P. D. (1968). The Mathematical Simulation of Chemical, Physical and Mechanical Changes Accompanying the Hydration of Cement, 5th Int. Congr. Chem. Cem., Tokyo, vol. 2, p. 321. 
689 [74] Van Breugel, K. (1995). Numerical simulation of hydration and microstructural 690 development in hardening cement paste (II): applications, Cem. Concr. Res., vol. 25, pp. $691 \quad 522-530$.

692 [75] Bentz, D. P., and Garboczi E. J. (1991). A digitized simulation model for microstructural 693 development, Ceram. Trans., vol. 16, pp. 211-226.

694 [76] Bullard, J. W. (2007). A three-dimensional microstructural model of reactions and 695 transport in aqueous mineral systems, Modell. Simul. Mater. Sci. Eng., vol. 15, pp. 711$696 \quad 738$.

697 [77] Navi, P., and Pignat, C. (1996).Simulation of cement hydration and the connectivity ofthe 698 capillary pore space, Advanced Cement Based Materials, vol. 4, pp.58-67.

699 [78] ASTM (2012). Standard Specification for Portland Cement. ASTM C150/150M, pp. 9.

700 [79] Mehta, P. K. (2009). Global Concrete Industry Sustainability. Concrete International, 701

702 [80] Russ, J. C. (1986). Practical Stereology, Springer, pp. 196.

703

[81] Marsh B. K. (1984). Relationships between engineering properties and microstructure 704 characteristics of hardened cement paste containing pulverized fuel ash as a partial cement replacement, PhD thesis, The Hatfield Polytechnic, UK.

[82] Farjas, J., and Roura, P. (2006). Modification of the Kolmogorov-Johnson-Mehl-Avrami rate equation for non-isothermal experiments and its analytical solution, Acta Materialia, vol. 54(20), pp. 5573-5579.

[83] Mirzahosseini, M.R., and Riding, K. A. (2014). Effect of Curing Temperature and Glass 710 Type on the Pozzolanic Reactivity of Glass Powder, Cement and Concrete Research, vol. 58, pp. 103-111. 